\title{
Cultural Computing - How Can Technology Contribute the Spiritual Aspect of Our Communication?*
}

\author{
Naoko Tosa \\ Kyoto University, Academic Center for Computing and Media Studies. \\ Yoshida Nihonmatsu-cho, Sakyo-ku, Kyoto, 606-8501, Japan \\ tosa@media.kyoto-u.ac.jp
}

\begin{abstract}
The author is carrying out technology studies to explore and expand human emotions, sensibility, and consciousness by making innovative use of artistic creativity. We develop interfaces for experiencing and expressing the "essence of culture" such as human feelings, ethnicity, and story. History has shown that human cultures have common and unique forms such as behavior and grammar. We suggest a computer model for that process and a method of interactive expression and experiencing cultural understanding using IT called "cultural computing". We particularly examine Japanese culture, although it is only a small subject of computing.
\end{abstract}

Keywords: Communication, Software, Information System, Cultural Computing, Interactive Art.

\section{Introduction}

"The ethnic crisis, the urban crisis, and the education crisis are interrelated. If viewed comprehensively all three can be seen as different facets of a larger crisis, a natural outgrowth of man's having developed a new dimension - the cultural dimension most of which is hidden from view. The question is, How long can man afford to consciously ignore his own dimension?" This phrase is from "The Hidden Dimension" by cultural anthropologist Edward T. Hall, 1966.

Nowadays, computers play an important roll in various ways in our life. Cellular phones, e-mails, websites, games as well as PCs are almost parts of our life, and they became the daily items or media. Computers were only 'machines to calculate something' at first, but now they are 'media for thinking and memorization support.'

Let us see the relation between traditional customs and computers. Computers are typically used for calculation to restore something or for historical simulation. Archiving the fading cultures with using computers are barely in the use of thinking and memorization support, but it isn't an effective application of the ability of computers which now treats multimedia and are connected in network. The present ages often communicate with someone who has another cultural background, so they are needed to understand the history of their culture and other cultures. Because the typical way

* Published in '10 Spring Forum of Society of Automotive Engineers of Japan, May 00, 2010. 
to understand them is to read the books or to go to the museum, understanding another culture with picking appropriate information is not so easy. Can we understand the culture using computers as 'media for thinking and memorization support'which became more suitable for network, mobile, and two-way communication by the development of information technology? This paper describes basic methodology of cultural computing, that is, to treat the essences of the deep-inside culture like sensitivity, national traits, or narratives. And it integrates them into verbal and nonverbal information, proposing the prosperity of the field that treats the experience of exchange between cultural experiences and culture models by using computer. The cultural computing, which is essential for the communication ability of future computer, introduces you to this new field which defines what humans have stored in each culture and it's history in forms of actions or grammars are sharing common or peculiar forms by showing some concrete methodology and some examples.

\section{Media for Thinking and Memorization Support}

\subsection{The Transcending Artist}

What is the aim of arts? This is very huge and heavy question, but if I dare to answer, it is 'the visualization of the status of someone's heart' in a word.

The value of arts is in contrary of the one of technologies. Great art works are having universal values that have not faded yet. On the other hand, old technologies are often selected and surpassed by other new ones. Media arts does transcend them, making new relationship between art and technology, and affecting to other various fields. In other words, arts transcend technologies and technologies transcend arts.

I was conscious of my way as a transcending artist, and determined to obtain global viewpoint instead of local, Japanese culture as the next step. I moved my base of research activity to Massachusetts Institute of Technology, USA. However, I faced the difference between cultures there. I noticed that there were the differences not only in our daily life, but also in the feelings, memories, sign, unconscious communications that are strongly related to their cultures. I noticed that extremely Japanesecharacterized expressions as well as global express had also been used in my works, although I had tried to express my artworks generally.

I have tried to assimilate myself into America at first, but it was difficult and I strongly realized that I am Japanese. I paid attention to actions and grammars that are seemed as 'Japanese culture' in America. I tried to expression the difference between American behaviors or grammars and Japanese ones in the arts.

At that time, I have met Sansui ink paintings (Japanese landscape paintings) of Sesshu. Sansui paintings are not landscape painting, but they are imagined scenery. This is in relation to the unconsciousness of occidental Jung's psychology. I discovered the way of unconscious communication to understand other cultures by using the components of unconsciousness in Sansui paintings.

I succeeded to create an interactive artwork, $\langle$ ZENetic Computer $\rangle$ by modeling the structure of Zen and Sansui, which are thought the very Japanese culture. After that, I created the Kanji inspiration 《i.plot》》 which gives relations between psychological associations and graphical images of ideograms. Furthermore, I 
produced 《Hitch Haiku》 system which supports creating the Haiku from several Kanji (Chinese character) input, using the template of 5-7-5 characters.

Surprisingly, when I exhibited these works in overseas, for example MIT, many Americans understood these works. This shows that these arts, transcending the time as history or culture, and the space as nations, became the media which people in other culture can understand, by picking up the structure of peculiar traditional Japanese culture through the computer.

\subsection{Cultural Poiesis}

By continuing these studies, I discovered that I could precede the methods of art and technology. That is, interactive works with computer modeling of Japanese culture can be brand new media that enable everyone to understand other cultures by touching them. Thus, obstacles between Japanese traditional culture that was thought as peculiar and other cultures were slowly disappeared.

To express a core of a culture based on the traditional culture model, by using computer. Many people from around the world can create their own Haiku or Zen, and send them to the world by the computer using traditional cultural model through the metaphor. Of course, computers can model not only Japanese cultural metaphor but also the world theater of Shakespeare, and it is possible to create Kabuki composed by the metaphor of the Globe Theatre. I think this can be called as the creation of the culture, the cultural computing.

I noticed that computers have a feature appropriate to create the new culture. Computer processes are divided into algorithms and data. We can seem them as types and contents! Handling the culture by the computer would lead to the creation of the new culture. The culture in that context is a poiesis (that means creation in Greek) of communication between different cultures.

\section{From Occidental Unconsciousness to Eastern Sansui Paintings}

\subsection{We Cannot Take Our Culture Off}

Have you had impatience about communication and thought, "Communications usually succeed, but why do they occasionally fail?" It fails because you communicate with someone supposing that they should be able to understand you. Communications are needed, however, for they cannot understand you. If you get it, you will find how to communicate with them calmly.

If we have understood all of us already, we do not need to communicate with each other. Japanese people has a strong pride of homogeneous race, so we apt to have relatively the same feelings, impressions and opinions about someone's actions, phenomena and a course of our society. As they typically call it a 'direct communication from mind to mind (Ishin-denshin in Japanese)', we are prone to think something supposing that they should understand us.

The characteristic of Japanese becomes obvious when we go abroad. That's because we face the condition that we cannot make ourselves understood even if we have thought they should be able to understand. Many other Japanese looks hard to be normal, like herbivorous animal living with carnivorous animals. 
In America, however, especially Anglo-Americans often communicate with considering that a person cannot understand them, I think. Actually, I had colleagues from Germany, Greece, Lebanon, Japanese, Chinese, French and Anglo-America. Southern Europeans usually use a nonverbal communication like Japanese, which makes me feel a sense of closeness. However, Anglo-Americans keep a distance when they communicate. Somehow, they do not open their hearts, or they tend to hesitate at showing their feelings. This fact shows that they communicate with considering that a person cannot understand them.

The same situation sometimes occurs when we communicate with a computer as well as a person.

In Boston, audio response systems often answer when we call to enter into contracts with a telephone or a gas service. Computers ask us, "My name is Alice (e.g.), please answer me to register." "May I ask your name, please?" "May I ask your address?" Those questions continue. And what is worse, the speech recognition sometimes fail. Then the computer says, "I couldn't recognize, please repeat that again?" Answering it three times will be the limits of our patience. One of what are good about American frontier spirit is this big-hearted and trendy disposition.

"Do people here really patient about computer operators?" I asked my friend and she advised me , "In that case, you should wait while human operator appears." She says that various things (computers or humans) meddle in phenomena, and extended the time we decide something. This analysis also shows the difference between Japanese who accustomed to communicate tacitly and Americans who accustomed not to communicate tacitly.

While I stayed at Boston, I realized by my experience that we should think communications occur only when people can't understand each other, considering the difference of their culture. Many times I experienced satisfaction of sympathy with someone whom I thought was not understandable, which is beyond expression. We cannot communicate freshly without this moment. If we communicate not only with discovering our errors, differences or sympathies but also with exchanging and amplifing our knowledge and feelings, the communication will transchend each cultures.

We obtained global comunication by adopting medica technologies in face-to-face communication which had been limited to a small community. E-mails, social networks, blogs enabled us to communicate more easily with people from around the world, beyond barriers of distance and culture. On the other hand, many people feel communications being more and more shallow these days. Rather, these shallow communications brought a recent typical face-to-face conversation, "Did you read my message?" Communications may be turning into extremely superficial communications, with taking off the tastes of cultures.

Ignoring this tendency will cause the decline in our communication ability which we have had as the basic instinct from ancient times. We immediately need the new communication media which can convey one's depth of feeling crossing the border of cultures. I knew it is realizable during my 2 years stay in Boston.

I wanted to create the communication media with which we can communicate deep feelings transcending the culture. As the result of my stay in Boston, I had this strong idea. 


\subsection{Technologies Combined with the Spirit}

I visited Western China for 10 days, in the later July 2002. The aim of this trip was to discuss with Tibetan doctors and philosophers, and to complete the fieldwork for my research theme that looks for the problems about arts, technologies and hearts.

Tibetans naturally have an idea that the medicine and the philosophy is the same. Doctors are philosophers, and are Buddhist priests at the same time. I was impressed by the nature that doctors see what is wrong in patient's heart at first.

Tibetan philosophy has an faith to give freedom to all the afflicted lives. Their thought is deeply related to consciousness, feelings, the space and lives, centering the bowels of mercy and wisdom. The cosmic view has to do with our essential problems, the wheel of life and the existence. Many cultures in Tibet include Buddhist Tantrism as the appreciation of the idea that life cycles.

We visited Arura Tibetan Medical Center. We discussed with five people including famous Dr. Denchi, the hierach and Buddhist philosopher, and Dr. Tanjinja who is nyingma (specialists for sadhana in Tibetan cabala). When we referred our spirituality of arts and the possibility of fusion between art and technology, they identified with us and said, "It is a possible idea as one of the figure of future religion." This encouraged us so much.

Tibetan Buddhists set the sprit of bodhisattva very important. This means to put off their tenacity to themselves and self-love, to have altruistic love. I noticed that this spirit is deeply related into interactive art.

Interactivity in art is shallow and the value is low if the purpose is up to selfassertive or communication of feeling. What is important is the interaction with having the sprit of bodhisattva and altruistic love. That is, if computer systems succeed to interact with having the sprit of bodhisattva, the interactivity of the system can deeply resonate the high spirit with other people.

I knew in my visit to Tibet that the Buddhism, which was born in India, has stayed in Tibet adjusting to the climate there and that the global consciousness is remaining there. I was impressed with the fact that we Japanese and Tibetan Buddhist are able to understand each other at a deep side of our spirit. I hoped to create something that Westerners can also understand the Buddhism, as a media expression using technologies. I just met the Sesshu, which critically affected my artworks after that.

\subsection{Meeting the Sansui}

I met the Sesshu at the exhibition "Sesshu - special exhibition at $500^{\text {th }}$ anniversary of his death" (Kyoto National Museum, 2002). I was fascinated with the world Sesshu had created. I did not have a special interest in Japanese culture before. For some reason, the Sansui world of Sesshu in that exhibition seemed a virtual reality which expressed his heart!

In old China, a Sansui picture was once about a landscape we wanted to watch forever, a place we wanted to go to play, a place we wanted to live, and a hometown of our heart in which we wanted to pass away. The Sansui picture is imagined scenery like that. Its bleeding, cracked, feathering lines of ink brush draw the movement of the heart. It makes us feel the color even if it is monochrome. 
I had an inspiration to compute the Sansui picture typically by Sesshu and the world of Zen which was expressed in Sansui picture. Zen makes us feel Japanese culture by its absence of absolutes, beauty sense of "Wabi-Sabi", and getting rid of the water from the Chinese garden with taking the Asian culture in. Many elements in Japanese culture are gathered in Sansui, like the Ume-Sansui (Sansui with Japanese aprlicot). I wanted to express the Sansui picture and Zen culture, centering the Japanese Zen.

Cultures consist of 'the God, the Buddhist image, a view of Life, a view of world'. They have been created, changed, opposed and fused with each other, and are irrational and rational. They, which have both irrationality and rationality, have seemed difficult to handle.

There was no research to make use of the hierarchy of Japanese culture to the computer logic in the existent computer technology. This is the reason why there are no arts expressing the deep historical 'culture' in large scale yet. Another reason is that everyone have paid attention to the uniqueness of Japanese culture and seemed the Japanese culture as Japanese superficial expressions.

On the other hand, technologies finds the mechanism of phenomena, and analyzes the elements of them with the structure. And the study finds new relationship between different things and constructs them, by reconstructing them, trying some combination of them and comparing them.

What we can make use of in creating new media arts are extracting the basic structure or thoughts of Japanese culture, modeling them or using them as tools with using the technology. Fresh media works or art works would likely be created by that. This method will bring about a great possibility to the advancement in media arts and interactive arts hereafter.

Thanks to the cooperation of Seigo Matsuoka, who is a researcher of Japanese Culture in Editorial Engineering Laboratory, we took a little advantage in this difficult challenge that we reconstruct the world of Zen which was expressed in Sansui picture on the computer. Though we needed three years, we reached to the unique system named $\langle$ ZENetic Computer $\rangle$ as the result.

We succeeded to construct the extremely futuristic interactive system by projecting a part of allegory or symbol in Sansui pictures, Yamato-e (Japanese traditional paintings), Haikus, Kimonos that reminds of the Japanese culture - the structure of the oriental thought, the structure of Buddhist philosophy and the mechanism of Japanese traditional culture - which rarely have featured by the computers before.

This system uses various symbols and allegories that are included in Buddhism, an oriental thought and the Japanese culture. This is because they include a plenty of implications, and they have extraordinary terms, figures or colors. There are many rules in Sansui pictures and the world of Zen. We discovered that computers can handle them, if we can select and extract them. For example, there are 'San-En' which is an expression of Sansui pictures, and 'Go-Un' (five elements which form a selfexistence) which is a function to recognize the human in Buddhism and so on.

The first exhibition of this system was in MIT museum. I wondered whether Westerners understand it or not. As a result, however, it was accepted by many Westerners and won the great popularity. Westerners had felt that Sansui pictures and Zen is extremely oriental and hard to approach, but they gave me impressions that they could understand them through the interaction with this system. I myself had an impression 
that we could achieved the initial goal to express Japanese culture in media, when I saw a American child interacting joyfully with this system.

After that, it was exhibited in SIGGRAPH, the international conference of CG, and Kodaiji, a Zen temple in Kyoto. Each exhibition won great popularity. This success of the experiment using this system made me certain that the 'cultural computing' which computes the culture is reasonable to set to my research goal.

\section{Structure of the Culture Becomes a Communication Technology}

\subsection{An Interaction to Reach the Racial Memory}

I was encouraged by the success of $\langle\langle$ ZENetic Computer $\rangle$, and felt that interaction that reaches the deep-inside racial memory was the research I wanted to realize as the next stage. From the dry interaction of computers to the friendly and impressive interaction. How to realize this challenge?

I tried to classify the types, structures and relationship of what supports racial memories in Japanese culture with my co-researcher, Seigo Matsuoka. Below is the detail:

1. Japanese natural climate: Japanese transient weather and nature, thought of transience like 'Monono-Aware', beauty senses like 'Wabi-Sabi', existential thought that loves present situation.

2. Relationships between Japanese culture and Asian one : Transformation from Chinese Sansui pictures to Japanese ones, Chinese gardens and grove gardens to the Japanese Rock Garden.

3. The syncretization of Shinto and Buddhism: The cultural structure that was reconstructed as a belief system, mixing the native faith and the Buddhism.

4. Characteristics of Japanese language: Waka poem, Haiku poem, Noh thater, and the script of Kabuki. And as applications, Honka-Dori, Uta-Makura, KakariMusubi, etc.

5. Japanese Design: Japanese designs are the most popular. Two-dimensional designs are Mon (armorital bearings), Ori (pattern of textiles), colors, paper patterns, lines for example. Three-dimensional dynamic designs are the design of Noh, Kabuki, etc.

On these bases, we can consult on various racial types of Japanese culture and the rear communication.

\subsection{Computers Do Not Have a Cultural Information Hierarchy}

Scientific technologies have developed Web2.0 like Google, Youtube, Wikipedia and SNS by which we can send our information more easily. Robot technologies are also developing new basic techniques to realize the superior functions that living things have. More specifically, they are global communication technologies including the movement functionality, manipulation system, distributed autonomous system for upgrading the intelligence. 
There is, however, no cultural information hierarchy that is needed to live with humans. Adding the local cultural information by cultural computing to here may contribute to create higher-level communication systems.

\section{Conclusion}

These methods of 'cultural computing' enables us to model and structure the deepinside essentials of culture like sensitivity, intuition, racial characteristics and narratives that we have not able to quantification. I have set my goal to realize the communication that moves one's racial characteristic expanding the present computer's communication ability to have an ability to reflect the difference in feelings, consciousness and memories, based on the culture. If these systems are realized, social practical and cultural information expression systems through the languages, voices and movies will be realized in various fields.

\section{References}

1. Tosa, N.: Cultural Computing. NTT Publishing (2009) (in Japanese)

2. Stafford, B.M.: Visual Analogy: Consciousness as the Art of Connecting. The MIT Press, Cambridge (2001)

3. Minsky, M.: Society of Mind. Simon \& Schuster (1988)

4. Hall, E.: The Hidden Dimension. Anchor (1990)

5. Nakatsu, R.: Future of Communications: How can technology Contribute the Spiritual Aspect of our Communications. Ohm-Sha Publishing (2010) (in Japanese)

6. Tosa, N., Matsuoka, S.: ZENetic Computer: Exploring Japanese Culture. The Journal of the International Society for Arts, Sciences and Technology: LEONARDO 39, 205-211 (2006) 